\title{
Bone Marrow Aplasia
}

National Cancer Institute

\section{Source}

National Cancer Institute. Bone Marrow Aplasia. NCI Thesaurus. Code C110960.

Depletion of stem cells in the bone marrow that results in the lack of production of hematopoietic cells. 